\title{
Saúde suplementar: os benefícios e desafios sobre o atendimento home care, sob a perspectiva da jurisprudência do STJ
}

\section{Supplementary health: the benefits and challenges on home care service, from the perspective of STJ jurisprudence}

\author{
Francisco Mauro Ferreira Liberato ${ }^{1 *}$, Rômulo Guilherme Leitão ${ }^{2}$
}

\begin{abstract}
RESUMO
A saúde suplementar é um assunto relativamente novo no Brasil, que demanda algumas necessidades especiais, como o home care, cujo atendimento domiciliar, algumas vezes, é negado administrativamente. E esta situação produz uma judicialização da questão, em que o órgão julgador é provocado a decidir, de forma justa e equilibrada, entre o direito do segurado e o dever legal e contratual das operadoras que atuam no ramo. Com isso, propõe-se uma discussão que analise os benefícios e desafios sobre o home care enfrentados pelo Judiciário, especialmente à vista dos precedentes do Superior Tribunal de Justiça, considerando no estudo a ausência de uma disciplina legal sobre a matéria em estudo. Para tanto, será desenvolvida uma pesquisa bibliográfica, teórica e documental, com abordagem qualitativa, referenciada em obras e, notadamente, em decisões do STJ. Como resultado da pesquisa, espera-se levantar informações úteis que contribuam para uma solução sensata em relação às demandas judiciais que versem sobre home care com vistas à concretização do direito fundamental à saúde, mas que sejam procedentes, sob o aspecto jurisprudencial, que compreende questões legais, contratuais, financeiras e técnicas.
\end{abstract}

Palavras-chave: Saúde suplementar. Home care. Judicialização. STJ.

\begin{abstract}
The supplementary health is a relatively new subject in Brazil, which requires some special needs, such as home care, whose home care is sometimes administratively denied. And this situation produces a judicialization of the issue, in which the judging body is provoked to decide, in a fair and balanced way, between the insured's right and the legal and contractual duty of the operators operating in the field. Thus, a discussion is proposed to analyze the benefits and challenges on home care faced by the Judiciary, especially in view of the precedents of the Superior Court of Justice, considering the absence of a legal discipline on the subject under study in the study. Therefore, a bibliographical, theoretical and documentary research will be developed, with a qualitative approach, referenced in works and, notably, in STJ decisions. As a result of the research, it is expected to raise useful information that contributes to a sensible solution in relation to the legal demands that deal with home care with a view to realizing the fundamental right to health, but which are valid, under the jurisprudential aspect, which includes issues legal, contractual, financial and technical.
\end{abstract}

Keywords: Supplementary health; Home care; Judicialization; STJ.

\footnotetext{
${ }^{1}$ Universidade de Fortaleza (UNIFOR).*E-mail maurolib@uol.com.br.

${ }^{2}$ Procurador do Município de Fortaleza e Professor da Universidade de Fortaleza (UNIFOR).
} 


\section{INTRODUÇÃO}

Alçada a direito fundamental a partir da vigente ordem constitucional, a saúde é classificada pela doutrina como direito de segunda dimensão, introduzida por meio do constitucionalismo social que floresceu no Brasil no século $\mathrm{XX}$, no período pós-Guerra, e por isto nasceu abraçada ao princípio da igualdade e da dignidade da pessoa humana.

Com efeito, o direito fundamental à saúde recebeu um destaque especial na Constituição de 1988, ocasião em que houve bastante preocupação do legislador com a efetividade dessa garantia ao cidadão, materializada nos artigos 6º 194 e 196, todos da Constituição Federal, cujos comandos são extensíveis ao setor privado que opera na área.

E, de acordo com a exegese extraída do artigo 197 da CF/88, as ações e serviços públicos de saúde são de relevância pública e, ainda que prestados pela iniciativa privada, o poder público os regulamenta e fiscaliza, dado o interesse público envolvido na matéria ${ }^{3}$. Assim, a relação contratual entre os planos de saúde e os usuários é regulada pelo Estado.

De seu turno, a saúde suplementar brasileira, embora encontre suas raízes na década de 1960, época em que algumas empresas do setor industrial e de serviços começaram a oferecer assistência à saúde a seus funcionários, a partir de um cenário político favorável, diante do crescimento econômico do país, foi institucionalizada a partir da Lei $\mathrm{n}^{\mathrm{o}}$ 9.656/1998 e constituiu um novo padrão de intervenção estatal no sistema de saúde suplementar, provocando alterações estratégicas e contratuais nos planos privados de assistência à saúde.

E, na especificidade da matéria, uma das prestações de serviço que vem causando controvérsia jurídica entre as partes contratantes diz respeito ao atendimento home care, cujo termo é importado do inglês ${ }^{4}$, que pode ser resumido à internação domiciliar, bem assim pressupõe a disponibilidade de diversas modalidades de atendimento médicodomiciliar em favor do segurado.

$\mathrm{O}$ atendimento assistencial home care, todavia, não foi regulamentado expressamente pela norma de regência, Lei 9.656/1998, a qual dispõe sobre os planos e

\footnotetext{
${ }^{3}$ Art. $4^{\circ}$, III, da Lei - Art. $4^{\circ}$ Compete à ANS: (...) III - elaborar o rol de procedimentos e eventos em saúde, que constituirão referência básica para os fins do disposto na Lei ${ }^{\circ}$ 9.656, de 3 de junho de 1998, e suas excepcionalidades.

${ }^{4}$ Em tradução livre, significa cuidado domiciliar.
} 
seguros privados de assistência à saúde. Daí surge a seguinte pergunta-problema: qual a medida que o Judiciário brasileiro pode adotar para efetivar a prestação jurisdicional e unificar a jurisprudência do STJ sobre home care, diante do vácuo legislativo sobre a matéria? No caso, a pretensão é confirmar a hipótese de que uma das soluções é a criação de varas e câmaras especializadas sobre o tema, de modo a proporcionar um direcionamento e aperfeiçoamento dos julgadores para o assunto em discussão.

Em reforço, a ausência de norma, completa e expressa, sobre o home care, a matéria suscita intermináveis discussões e, por esta razão, tem provocado uma crescente demanda nos tribunais do país, cujos inconformismos, muitas vezes, deságuam no Superior Tribunal de Justiça (STJ) que tem a missão, através de métodos de integração e interpretação, de resolver a questão posta a debate. Demais disso, a solução da controvérsia envolve a utilização de postulados como o mínimo existencial aplicado à saúde suplementar e a capacidade técnico-financeira dos planos privados de assistência à saúde.

A propósito, a noção de mínimo existencial remete à ideia de um direito que reúne um conjunto de ações ou prestações que assegure ao cidadão uma vida digna. $\mathrm{Na}$ concepção de Peter Härberle (2003), o mínimo existencial possui uma relação direta com a dignidade da pessoa humana e com o Estado Democrático de Direito, na medida em que realiza a missão de justiça social, concretizando o direito fundamental à saúde. Tal princípio pode ser perfeitamente aplicado em contratos privados de plano de saúde, mormente quando se pleiteia a prestação de serviços essenciais, que comprometam as funções vitais do segurado.

Há diversas decisões no âmbito do STJ sobre a matéria examinada, nem todas no mesmo sentido, em função das peculiaridades do caso concreto. E, mesmo com a publicação de algumas súmulas ${ }^{5}$ e aprovação de temas sobre saúde ${ }^{6}$, ainda se encontram precedentes divergentes nos tribunais do país.

Ainda, há algumas orientações passadas pelo Superior Tribunal de Justiça que devem ser seguidas pelos juízos e tribunais inferiores, a fim de pacificar conflitos e inibir demandas multiplicadas sobre a mesma matéria. Muito embora isto não impede a análise autônoma de cada conflito posto à discussão, realizada pelas autoridades judiciais que

\footnotetext{
${ }^{5}$ De que são exemplos: as súmulas 302, 469 (cancelada), 597, 608 e 609.

${ }^{6}$ Alguns temas com teses firmadas no STJ: 84, 106, 686, 766 e 952.
} 
estão mais próximas do problema e que, inclusive, enfrentam o assunto com ampla dilação probatória.

De todo modo, o tema é complexo diante dos dissídios jurisprudenciais verificados nos tribunais pátrios, cujas discussões sobem ao Superior Tribunal de Justiça que tem o poder de pacificar o entendimento sobre a matéria. A propósito, importante destacar que a Segunda Seção do STJ, em abril de 2018, resolveu cancelar o verbete sumular 469, cujo comando determinava: "aplica-se o Código de Defesa do Consumidor aos contratos de plano de saúde". Em seguida, foi aprovada a súmula 608 que tem o seguinte enunciado: "Aplica-se o Código de Defesa do Consumidor aos contratos de plano de saúde, salvo os administrados por entidades de autogestão".

$\mathrm{Na}$ feitura do artigo, desenvolver-se-á uma pesquisa do tipo bibliográfica, com ênfase qualitativa, que envolve uma abordagem teórica e empírica. O referencial teórico se fundamentará em normas, doutrina e em dados secundários, com especial destaque às decisões judiciais do Superior Tribunal de Justiça.

Nesse ritmo, no primeiro tópico do artigo será abordada a judicialização do home care, em que se exporão os debates e entendimentos legal, doutrinário e jurisprudencial sobre o assunto. Em seguida, no segundo capítulo, analisar-se-á as decisões construídas no bojo dos paradigmáticos Agravo Interno no Agravo no Recurso Especial $\mathrm{n}^{\circ}$ 1450651/SP e Recurso Especial n ${ }^{o}$ 1712163/SP. No capítulo seguinte, abrir-se-á a discussão acerca da necessidade de uniformização da jurisprudência dos julgados em matéria de saúde suplementar, mormente em função do vazio legislativo sobre home care, seguida da sugestão de criação de varas e câmaras especializadas sobre o tema em discussão.

Assim, é induvidosa a relevância e discussão da temática pesquisada, que envolve a sociedade, planos de saúde e o Judiciário, tanto que o Relatório Anual de Gestão da Agência Nacional de Saúde Suplementar, exercício 2020 (ANS, 2021, p. 16), aponta que, no ano passado, foram analisadas a atuação de 315 operadoras de plano de saúde, que têm cerca de 56 milhões de usuários, "representando $76 \%$ do mercado de saúde suplementar".

Em síntese, considerando que, diante da ausência de disciplina legal sobre o home care, buscam-se informações importantes sobre a matéria a partir de construções jurisprudenciais, notadamente firmadas no âmbito do Superior Tribunal de Justiça, órgão responsável pela orientação e unificação da interpretação da lei federal em todo o país, as quais serão enfrentadas adiante. 


\section{A JUDICIALIZAÇÃO DO HOME CARE: DISCUSSÕES E ENTENDIMENTOS SOBRE A ATENÇÃO DOMICILIAR}

A relação contratual existente entre as operadoras de plano de saúde e os usuários ${ }^{7}$, regida ou não pelo Código de Defesa do Consumidor, desencadeia muitas discórdias, dentre os motivos, destaca-se o fato de que o home care não é expressa e satisfatoriamente disciplinado na lei. Por isto, o referido atendimento domiciliar dificilmente é previsto no pacto firmado entre os contratantes e, de toda forma, sempre há margem para controvérsias.

Além disso, a Agência Nacional de Saúde Suplementar (ANS), criada pela Lei 9.961/2000 (BRASIL, 2000), tem natureza jurídica de autarquia sob regime especial, vinculada ao Ministério da Saúde, com autonomia administrativa, financeira e patrimonial, e não possui, dentre as suas competências legais, o poder de modificar contratos individuais, muito menos interpretar cláusulas pactuadas, em casos concretos, que gerem dúvidas na sua execução.

Por isso, as divergências contratuais que surgem entre a operadora de saúde e o usuário são resolvidas no âmbito do Poder Judiciário. E a judicialização no caso do home care provoca, além do emprego de técnicas de integração e métodos interpretativos, uma análise que é solucionada à base do binômio necessidade (difícil situação clínica do segurado cuja negativa do tratamento domiciliar porá em risco a sua vida) e possibilidade (previsão legal, contratual e observância ao equilíbrio econômico-financeiro).

A situação ora debatida remete à expressão “casos difíceis" (hard cases), de Ronald Dworkin (2002), segundo o qual quando uma determinada ação não puder ser submetida a uma regra expressa do Direito, pré-estabelecida, ainda assim o julgador tem o dever de resolver a causa, com base na ideia de inadmissão da teoria de sentença non liquet, conforme a orientação normativa passada no artigo $4^{\circ}$ da lei de introdução às normas do Direito brasileiro $^{8}$, em que autoriza o juiz a decidir o caso, mesmo diante da omissão legislativa, de acordo com a analogia, os costumes e os princípios gerais do direito (BRASIL, 1942).

\footnotetext{
${ }^{7}$ Que normalmente é um contrato de adesão, em que o interessado adere às regras pré-estabelecidas pela pessoa jurídica fornecedora de planos de saúde.

${ }^{8}$ Ementa dada pela Lei 12.376/2010 (BRASIL, 2010).
} 
$\mathrm{O}$ autor pondera ainda que "O juiz continua tendo o dever, mesmo nos casos difíceis, de descobrir quais são os direitos das partes, e não de inventar novos direitos retroativamente" (DWORKIN, 2002, p. 127). Ainda assim, concedendo ou negando um pleito da parte, a decisão judicial deve ser fundamentada, de acordo com o comando expresso no artigo 93, IX da CF/88.

Do mesmo modo, pertinente à observação de que, geralmente, o segurado ajuíza uma ação ordinária de obrigação de fazer, com o fim de compelir a operadora privada a providenciar a internação domiciliar do beneficiário, considerando que se trata de uma demanda que provoca discussão fático-probatória: demonstração da gravidade da doença perícia, instrução e oitiva. De fato, o Judiciário deve decidir a ação proposta à vista do equilíbrio e da justeza, que se alcança através do conhecimento amplo e atento às peculiaridades da causa.

Para tanto, na situação na qual se pretende o atendimento home care deve ser precedida de alguns requisitos, conforme reiteradamente vem decidindo o Superior Tribunal de Justiça. Por exemplo, se a doença é coberta pelo plano e houver prescrição médica indicativa de internação domiciliar do paciente-usuário, em razão de sua difícil situação médico-clínica, mesmo não havendo previsão contratual do home care, a operadora não pode recusar à atenção domiciliar, segundo reafirmado no AgInt no AREsp 1450491/RJ (BRASIL, 2020).

E, além da condenação em danos morais por conta da recusa injustificada no atendimento domiciliar (BRASIL, 2021), há outras orientações proclamadas pelo Superior Tribunal de Justiça, inclusive sobre as condições de implementação do home care, como nas diretrizes passadas no Recurso Especial $n^{\circ} 1.662 .103 / \mathrm{SP}$, julgado em dezembro de 2018, adiante transcrito, na passagem que interessa:

RECURSO ESPECIAL. SAÚDE SUPLEMENTAR. AÇÃO DE OBRIGAÇÃO DE FAZER. NEGATIVA DE COBERTURA DE PLANOS DE SAÚDE. CLÁUSULAS LIMITATIVAS DEVEM SER REDIGIDAS COM CLAREZA. HOME CARE. INTERNAÇÃO DOMICILIAR. ABUSIVIDADE DA NEGATIVA DE FORNECIMENTO DA OPERADORA. CONFIGURADA. PACIENTE TETRAPLÉGICA, COM SEQUELAS NEUROLÓGICAS E ALIMENTAÇÃO POR SONDA GÁSTRICA. DANO MORAL. DEMONSTRAÇÃO NECESSÁRIA. MERO ABORRECIMENTO. SÚMULA 7/STJ.

(...) 2- Os propósitos recursais consistem em definir: i) se a operadora de plano de saúde está obrigada ao fornecimento de atendimento domiciliar (home care), apesar da ausência de previsão contratual; ii) acaso devida a cobertura, se sua negativa em favor da beneficiária produziu dano moral passível de compensação. (...) 5- A internação 
domiciliar (home care) constitui desdobramento do tratamento hospitalar contratualmente previsto que não pode ser limitado pela operadora do plano de saúde. Precedentes. 6- Recomenda-se observar circunstâncias relevantes para a internação domiciliar, assim expostas exemplificativamente: i) haver condições estruturais da residência, (ii) real necessidade do atendimento domiciliar, com verificação do quadro clínico do paciente, (iii) indicação do médico assistente, (iv) solicitação da família, (v) concordância do paciente e (vi) não afetação do equilíbrio contratual, como nas hipóteses em que o custo do atendimento domiciliar por dia não supera o custo diário em hospital. Precedentes. (...) 8- Na hipótese concreta, primeiro e segundo graus de jurisdição registraram que a negativa de cobertura não produziu piora no estado de saúde da beneficiária do plano de saúde, e nenhum dano que ultrapasse o dissabor cotidiano. Recursos Especiais conhecidos e não providos (BRASIL, 2018, on line).

Existe ainda o precedente no âmbito do Superior Tribunal de Justiça de que, conquanto não seja aplicável o Código de Defesa do Consumidor aos contratos de plano de saúde que atuam, exclusivamente, sob a modalidade de autogestão ${ }^{9}$, de acordo com o comando da súmula 608/STJ, mas esta situação não mitiga o princípio da força obrigatória do contrato, sendo aplicável, em substituição, as regras previstas no Código Civil de 2002 em matéria contratual, especialmente em relação à boa-fé objetiva e os desdobramentos dela decorrentes, como assentado no AgInt no AREsp 835.892/MA, da lavra do ministro-relator Antônio Carlos Ferreira (BRASIL, 2019).

Outra diretriz jurisprudencial aplicada sobre os planos de saúde, especialmente no polêmico tratamento domiciliar, é que este atendimento constitui desdobramento do tratamento hospitalar, contratualmente previsto. E as cláusulas restritivas de direito devem ser escritas com destaque, permitindo imediata e fácil compreensão, bem assim que, na dúvida, as cláusulas devem ser interpretadas de modo favorável ao usuárioconsumidor, de acordo com a dicção do artigo 54, $\S 4^{\circ}$ do CDC, entendimento reafirmado no Recurso Especial no 181.6768/PR (BRASIL, 2020).

Cumpre observar, no entanto, que há precedentes favoráveis aos planos de saúde, decididos no âmbito do Superior Tribunal de Justiça, como a tese firmada no tema 990, sob o regime de recurso repetitivo (no REsp 1712163/SP), com o seguinte texto: "as operadoras de plano de saúde não estão obrigadas a fornecer medicamento não registrado pela ANVISA". E este comando tem gerado reflexos em alguns julgados, inclusive sobre home care.

\footnotetext{
${ }^{9}$ Refere-se àquelas pessoas jurídicas que atuam no ramo, sem fins lucrativos, vinculadas ou não a entidades públicas ou privadas, de que é exemplo a GEAP; diferentemente das operadoras particulares que obtêm lucro no mercado, como a Unimed.
} 
Realmente, parte da jurisprudência recente do STJ está orientada no sentido de que não é abusiva a restrição, por cláusula expressa no contrato com as operadoras, de medicamentos de uso domiciliar. Porém, este entendimento é excetuado em relação aos fármacos antineoplásticos orais, em tratamento contra o câncer, medicação destinada a tratamentos em home care, além de remédios com cobertura obrigatória prevista pela ANS e registrados na ANVISA, cujo posicionamento é encontrado no REsp 1.692.938/SP $\left(\right.$ BRASIL, 2021) ${ }^{10}$.

Ainda sobre a decisão retro, importante evidenciar que os planos de saúde não estão, em regra, obrigados a custear qualquer medicamento, ainda que prescritos pelo médico assistente para uso doméstico, que possam ser adquiridos facilmente em farmácias. Outra, a relevância da Resolução Normativa no 310/2012 (BRASIL, 2012), que facultou às operadoras de saúde a possibilidade de ofertar aos beneficiários de planos individuais, familiares ou coletivos por adesão e coletivos empresariais, por meio de contrato acessório, medicação de uso domiciliar.

\section{ANÁLISE DO AGRAVO INTERNO NO AGRAVO NO RECURSO ESPECIAL 1450651/SP E DO RECURSO ESPECIAL 1712163/SP}

O tema saúde realmente suscita diversos debates e a discussão conduzida no AgInt no AREsp 1450651/SP (BRASIL, 2019), sob a competência do Superior Tribunal de Justiça, trouxe informações úteis que contribuem para a pacificação de discussões sobre a saúde suplementar, especificamente sobre o home care.

Nas instâncias ordinárias, a recorrente, Amil Assistência Médica Internacional S.A, foi condenada em danos morais porque negou, injustificada e abusivamente, a internação

\footnotetext{
${ }^{10}$ (...) É lícita a exclusão, na Saúde Suplementar, do fornecimento de medicamentos para tratamento domiciliar, isto é, aqueles prescritos pelo médico assistente para administração em ambiente externo ao de unidade de saúde, salvo os antineoplásicos orais (e correlacionados), a medicação assistida (home care) e os incluídos no Rol da ANS para esse fim. Interpretação dos arts. 10, VI, da Lei n ${ }^{\circ}$ 9.656/1998 e 19, § $1^{\circ}$, VI, da RN no 338/2013 da ANS (atual art. 17, parágrafo único, VI, da RN no 465/2021). 4. Os medicamentos receitados por médicos para uso doméstico e adquiridos comumente em farmácias não estão, em regra, cobertos pelos planos de saúde. 5. As normas do CDC aplicam-se apenas subsidiariamente nos planos de saúde, conforme previsão do art. 35-G da Lei no 9.656/1998. Ademais, em casos de incompatibilidade de normas, pelos critérios da especialidade e da cronologia, há evidente prevalência da lei especial nova. 6. A previsão legal do art. 10, VI, da Lei $\mathrm{n}^{\circ}$ 9.656/1998 não impede a oferta de medicação de uso domiciliar pelas operadoras de planos de assistência à saúde (i) por liberalidade; (ii) por meio de previsão no contrato principal do próprio plano de saúde ou (iii) mediante contratação acessória de caráter facultativo, conforme regulamentação da $\mathrm{RN} \mathrm{n}^{\circ}$ 310/2012 da ANS.
} 
sob o regime home care a um usuário. Na ocasião, o Tribunal de Justiça de São Paulo (TJSP) aplicou a súmula $90^{11}$ da própria corte estadual, bem assim que a frustração acentuada, motivada pela falta do plano, ultrapassou o simples aborrecimento e atentou contra a dignidade humana.

A seguradora insurgente alegou, desde o início, que a decisão ofendeu os artigos 10 e 12 da Lei 9.656/98, o artigo 54, $\$ 4^{\circ}$ do Código de Defesa do Consumidor, até porque redigiu com destaque as cláusulas que restringiam o direito do usuário, bem como afrontou o artigo 188 do Código Civil, haja vista que praticou o ato no exercício regular de seu direito, reconhecido no pacto ajustado.

Além disso, a empresa de plano de saúde sustentou que somente está obrigada nos termos do contrato celebrado, no bojo do qual havia cláusulas limitativas e restritivas de direito, de maneira que a sua conduta não podia ser considerada abusiva, dada a ausência de previsão de tratamento domiciliar, portanto, inexistente o dano extrapatrimonial postulado pelo beneficiário ante a ausência de ilicitude na negativa da cobertura do tratamento postulado.

Entretanto, o STJ não acolheu as versões da entidade privada de saúde, hipótese em que consagrou o entendimento de que as operadoras que prestam serviços remunerados aos usuários, como é o caso da recorrente, que, apesar de ser regida pela Lei $\mathrm{n}^{\circ}$ 9.656/1998, enquadra-se também no conceito de fornecedora, submetendo-se às regras do código consumerista. E as normas incidem conjuntamente, mormente porque disciplinam contratos de longa duração e que lidam com bens sensíveis, como a manutenção da vida do segurado.

O tribunal superior ratificou o entendimento de que a cláusula ajustada, que excluiu a cobertura do tratamento domiciliar (home care) e vedou absolutamente a internação domiciliar como alternativa de substituição à internação hospitalar é considerada abusiva, ainda que o tratamento médico em domicílio não tenha sido incluído no rol de procedimentos mínimos obrigatórios que devam ser oferecidos pelos planos de saúde, na esteira do que preceituam os artigos 423 e 424 do Código Civil (BRASIL, 2002).

Ainda, a situação examinada se revela incompatível com a equidade e a boa-fé, bem assim coloca o usuário-consumidor em situação de extrema desvantagem, de acordo com a orientação passada no artigo 51, IV da Lei 8.078/1990 (BRASIL, 1990). Por estas

\footnotetext{
${ }^{11}$ Havendo expressa indicação médica para a utilização dos serviços de home care, revela-se abusiva a cláusula de exclusão inserida na avença, que não pode prevalecer.
} 
razões, confirmou a condenação da operadora inconformada em danos morais, como forma de ressarcimento ao abalo moral oriundo da recusa injustificada de cobertura securitária médica, que inclusive agravou a situação de aflição psicológica e de angústia do paciente segurado, já abalado em decorrência da doença.

Os ministros da Terceira Turma de Direito Civil reforçaram que o serviço de saúde domiciliar é mais benéfico ao paciente, visto que proporciona um tratamento humanizado junto da família e no seu lar, aumentando as chances e o tempo de recuperação, sofrendo menores riscos de novas internações e de contrair infecções e doenças hospitalares, de igual modo, em muitos casos, é mais vantajoso para o plano de saúde, com a otimização de leitos hospitalares e a redução de custos, como diminuição de gastos com pessoal, alimentação, lavanderia, hospedagem (diárias de profissionais), dentre outros.

No entanto, a referida Turma julgadora estabeleceu algumas condições para a conversão da internação hospitalar em domiciliar: haver condições estruturais da residência; de real necessidade do atendimento domiciliar, com verificação do quadro clínico do paciente; da indicação do médico assistente; da solicitação da família; da concordância do paciente; e da não afetação do equilíbrio contratual, como nas hipóteses em que o custo do atendimento domiciliar por dia não supera o custo diário em hospital. Os ministros advertiram ainda que, na recusa ao custeio da internação domiciliar por questões financeiras, a operadora deverá demonstrar o alegado com dados concretos e dar oportunidade ao usuário de complementar o valor de tabela.

Assim, com esses fundamentos, o tribunal superior concluiu que a tentativa de modificação meritória do acórdão estadual demandaria reexame fático-probatório, procedimento vedado pela súmula 7 do STJ, por isso, desproveu o AgInt no AREsp 1450651/SP da operadora de plano de saúde.

No que concerne ao segundo caso concreto, referente ao Recurso Especial $\mathrm{n}^{\circ}$ 1712163/SP (BRASIL, 2018), julgado pela Segunda Seção do STJ, sob a lavra do Ministro Moura Ribeiro, enfrentou o apelo nobre da Amil Assistência Médica Internacional S.A (AMIL), restando prejudicado o recurso da particular segurada. $\mathrm{Na}$ instância de primeiro grau foi proposta uma ação cominatória da usuária contra a AMIL e Itauseg Saúde S.A.

O pedido autoral foi julgado procedente pelo juízo singular, inclusive com deferimento de antecipação de tutela em face da seguradora. Assim, as partes apelaram ao tribunal de segunda instância, que negou provimento às duas insurgências, fixando o 
entendimento de que, se a doença é coberta pelo plano, não pode a seguradora restringir o tratamento, sendo desimportante que o tratamento esteja excluído do contrato e se trata de medicamento importado ou domiciliar, cujo tratamento deve seguir as recomendações clínicas do médico assistente do usuário.

Conveniente sublinhar que a apelação da autora atacou, exclusivamente, a decisão que arbitrou honorários por equidade, mesmo diante da natureza condenatória da sentença, que julgou procedente a sua pretensão. A partir daí, ambos os polos interpuseram Recurso Especial.

Através do recurso, a operadora inconformada pretendeu reverter o aresto recorrido que a condenou a custear o medicamento utilizado pela segurada, no seu tratamento contra a hepatite C, cobrindo as despesas havidas com Harvoni (sofosbuvir e ledispavir), sob a tese de que havia exclusão contratual expressa em relação a tais medicamentos, até porque se tratava de medicamento importado, sem o devido registro na ANVISA, portanto, tratando-se de medicamento não nacionalizado e proibida a entrada no país.

O Relator do recurso, percebeu o grande número de recursos com base em idêntico fundamento, configurando o caráter multitudinário da discórdia, destacou o presente feito como recurso especial representativo da controvérsia, para fins de aplicação do art. 1.036, $\S 5^{\circ}$, do NCPC, razão pela qual o afetou para julgamento pela Segunda Seção, sob o rito dos recursos repetitivos, surgindo o tema $990^{12}$, segundo o qual não se pode exigir dos planos de saúde o fornecimento de fármacos que não tenham registro na ANVISA, entendimento firmado no âmbito do REsp 1726563/SP (BRASIL, 2018) e do REsp $\mathrm{n}^{\circ}$ 1712163/SP (BRASIL, 2018).

O Ministério Público Federal se manifestou pelo desprovimento dos recursos especiais das partes sustentando a versão de que as operadoras de planos de saúde estavam obrigadas a fornecer medicamento importado, sem registro na ANVISA, em situações excepcionais.

Todavia, o órgão colegiado concluiu pelo ato lícito da operadora que excluiu do tratamento médico o fármaco importado, em síntese, sob o fundamento de que é importante o respeito à exigência de registro do medicamento na Agência Nacional de Vigilância Sanitária. Ainda, que as normas do CDC se aplicam apenas subsidiariamente aos contratos entre usuários e suas operadoras, conforme dicção do art. 35-G da Lei $\mathrm{n}^{\circ}$

\footnotetext{
${ }^{12}$ As operadoras de plano de saúde não estão obrigadas a fornecer medicamento não registrado pela ANVISA.
} 
9.656/1998, razão pela qual, nas hipóteses de aparente conflito de normas, pelos critérios da especialidade e da cronologia, devem prevalecer as normas de controle sanitário, que visam ao bem comum.

À vista da exposição, o STJ deu parcial provimento ao REsp 1712163/SP, manejado pela AMIL, para desobrigá-la ao fornecimento do fármaco à usuária. Porém, foi registrado no acórdão que tal medicamento fora registrado na ANVISA, a partir de 04/12/2017 (durante o trâmite recursal), quando então a recorrente foi obrigada a fornecer tal medicamento, daí porque o seu recurso foi provido em parte. Finalmente, a partir do recurso repetitivo em análise, foi fixada a seguinte tese: As operadoras de plano de saúde não estão obrigadas a fornecer medicamento não registrado pela ANVISA (tema 990).

\section{DISCUSSÃO ACERCA DA NECESSIDADE DE UNIFORMIZAÇÃO DA JURISPRUDÊNCIA E ESPECIALIZAÇÃO NOS JULGAMENTOS SOBRE O TEMA SAÚDE SUPLEMENTAR}

À vista dos precedentes do Superior Tribunal de Justiça, analisados anteriormente, que enfrentam pontos convergentes e divergentes sobre saúde suplementar, muitas vezes em razão de uma ausência de disciplina legal acerca da matéria, levanta-se um outro debate: a importância da uniformização da jurisprudência sobre o tema e a consequente necessidade de especialização de varas e câmaras nos tribunais do país para julgamento sobre saúde suplementar.

E a ideia ganha relevo no momento em que se depara com uma preocupante realidade que revela dissídios pretorianos entre os tribunais pátrios, ou mesmo internamente nos órgãos colegiados, que versam sobre o mesmo assunto, home care, por exemplo. E isto atenta contra a eficiência jurisdicional e, sobretudo, contra o princípio da segurança jurídica. Sobre o objeto abordado, importante a observação de que:

a orientação divergente decorrente de turmas e câmaras, dentro de um mesmo tribunal - no mesmo momento histórico e a respeito da aplicação de uma mesma lei - representa grave inconveniente, gerador da incerteza do direito, que é o inverso do que se objetiva com o comando contido numa lei, nascida para ter um só entendimento (ASSIS; ALVIM NETO; ALVIM, 20212, p. 742).

$\mathrm{Na}$ dimensão considerada, há a teoria dos precedentes, oriundo da common law, cuja proposta se fundamenta na ideia de construção de precedentes que consolidem e privilegiem entendimentos judiciais, consideradas as particularidades dos casos 
examinados. E tal instituto ampara a teoria segundo a qual os intérpretes têm o dever funcional de seguir os julgados já proferidos em situações idênticas, notadamente os acórdãos dos tribunais superiores (TUCCI, 2004).

Nesse contexto, conveniente ponderar sobre o incidente de resolução de demandas repetitivas, previsto no Código de Processo Civil de 2015 (BRASIL, 2016) e nos regimentos internos dos tribunais do país, cuja instauração pode ser requerida pelas partes, Ministério Público, Defensoria Pública, ou pelo juiz ou relator de ofício ${ }^{13}$, de maneira que a ferramenta processual se presta também para combater risco de ofensa à isonomia e à segurança jurídica ${ }^{14}$, diante de desestabilidades e dissensos jurisprudenciais.

Além do mais, ter um plano de saúde é, hoje, o terceiro maior desejo do brasileiro, perdendo apenas para a educação e moradia própria, segundo pesquisa do Ibope (LEITE, 2021). E a consequência direta desse aumento do número de usuários do serviço privado de assistência médica é o crescente volume de demandas jurídicas relacionadas a planos de saúde, por conta de divergências contratuais. O Conselho Nacional de Justiça concluiu um estudo em que "O número de demandas judiciais relativas à saúde aumentou 130\% entre 2008 e 2017, enquanto o número total de processos judiciais cresceu 50\%" (BRASIL, 2021, p. 13).

Em razão dessa estatística preocupante, é bastante importante o papel desempenhado pelo Superior Tribunal de Justiça na pacificação do tema que envolve o home care, irradiando orientação aos tribunais de segundo grau e juízes singulares do país. Mas esta medida não é suficiente para enxugar o número de ações que versam sobre saúde suplementar, sendo necessária a contribuição dos demais órgãos judiciários.

Desse modo, como exemplo de contribuição que visa conferir celeridade às demandas de saúde, bem como à sedimentação da jurisprudência sobre a matéria, alguns tribunais estaduais encontraram como solução eficaz a especialização de varas e câmaras de julgamento sobre saúde, cingindo-se competência específica para a apreciação das ações que envolvam assistência médica.

A propósito, desde 2013 o Tribunal de Justiça do Rio de Janeiro regulamentou o funcionamento das Câmaras especializadas em Direito do Consumidor. De acordo com a corte fluminense, as cinco novas câmaras cíveis com competência especializada em Direito do Consumidor foi uma iniciativa inédita na justiça brasileira e tinha como

\footnotetext{
${ }^{13}$ Vide artigo 977 do CPC/2015.

${ }^{14}$ Disposto no artigo 976 do CPC/2015.
} 
objetivo agilizar o julgamento de processos, aumentar a capacidade de processamento de ações cíveis, tornando negativo o saldo entre recursos recebidos e julgados no TJRJ (ASSESSORIA DE IMPRENSA DO TJRJ, 2013).

Por igual, em 2018, o Tribunal de Justiça do Estado do Piauí, “aprovou projeto de resolução que acrescenta o parágrafo único ao art. 81-A da Resolução no 02, de 12 de novembro de 1987 , dotando a $4^{\text {a }}$ Câmara de Direito Público do TJ de competência privativa para o julgamento de recursos que tenham por objeto o direito à saúde pública" (SILVA, 2021, on line), que também contribuiu para a agilização de julgamentos sobre saúde.

Em sentido semelhante, a experiência do Tribunal de Justiça do Estado do Ceará é com o Núcleo de Apoio Técnico ao Judiciário (NAT-JUS), composto por médicos e farmacêuticos, que tem como função elaborar notas técnicas e pareceres para auxiliar os juízes nas decisões que envolvam matérias de saúde. E desde a sua criação, em novembro de 2016, até julho de 2020, o Nat-Jus elaborou 453 notas técnicas e pareceres que auxiliaram juízes em decisões que envolviam matérias de saúde (CEARÁ, 2020).

Enfim, como observa Braga Netto (2020), a jurisprudência tem assumido uma importante função na construção da ordem constitucional democrática, no que concerne ao desenvolvimento efetivo de soluções que privilegiam a dimensão existencial das relações jurídicas. Dessa maneira, a jurisprudência é, seguramente, um agente operante na busca pela proteção dos direitos fundamentais, especialmente em relação à saúde, delineando conceitos normativos nos casos concretos.

\section{CONSIDERAÇÕES FINAIS}

O legislador constitucional prevê um sistema sanitário harmônico que consagra a saúde como um direito fundamental de todos, bem assim atribui ao Estado a competência para regular, fiscalizar e controlar os serviços prestados na área da saúde, ainda que prestada pela iniciativa privada. Por outro lado, a Constituição Federal e a legislação ordinária não asseguram o acesso irrestrito a qualquer tratamento ou medicamento, mas busca promover o uso racional e seguro desses produtos em termos de qualidade, quantidade e eficácia.

Ainda, em relação à saúde suplementar, inexiste uma normatização completa e satisfatória sobre a matéria, tanto que o home care não figura no rol de procedimentos 
obrigatórios regulados pela Agência Nacional de Saúde Suplementar, o que provoca a frequente intervenção do Judiciário para disciplinar a controvérsia entre o plano de saúde e o usuário. Por esta razão se verifica o crescimento exponencial de demandas referentes ao fornecimento de atendimento domiciliar.

Diante desse quadro, o Superior Tribunal de Justiça, além de competente para uniformizar a interpretação da lei federal em todo o país, vem solucionando as múltiplas causas que chegam à corte sob a forma de decisões que formam jurisprudências sobre o assunto, destacadas ao longo deste artigo, de modo a influenciar as instâncias inferiores sobre os conflitos na saúde suplementar.

Conquanto se deva considerar as peculiaridades dos diversos casos concretos que sobem ao Superior Tribunal de Justiça, mas, de modo geral, a corte superior possui orientação firme no sentido de que a operadora pode estabelecer as doenças que terão cobertura, porém não o tipo de tratamento prescrito pelo médico assistente, inclusive experimentais, quando essencial para garantir a saúde ou a vida do usuário, sendo ainda abusiva a recusa, injustificada, da operadora em arcar com a cobertura do medicamento prescrito pelo profissional, e a recusa, sem justo motivo, gera, em regra, dano moral em favor do beneficiário.

Assim, o Tribunal da Cidadania vem enfrentando as demandas com fundamento na norma dos planos de saúde, Lei 9.656/1998, bem como no Código de Defesa do Consumidor em relação aos contratos pactuados com operadoras que não operam à base de autogestão. Ademais, a corte emprega técnicas de integração e métodos interpretativos para a formação de decisões equilibradas e justas.

Mas, a solução ideal para este gargalo, que assoberba o Poder Judiciário e, de certo modo, compromete a eficiência da prestação jurisdicional, seria a regulamentação normativa específica, construída à luz dos princípios e regras constitucionais que regem o tema saúde, dentre outros, fixando parâmetros de cobertura, condições de pagamento e critérios para concessão de atendimento domiciliar, enquanto forma de assegurar que o segurado não sofrerá abusos.

Nesse sentido, as instâncias ordinárias devem contribuir com o aperfeiçoamento e pacificação dos conflitos que envolvem o home care, com a criação de varas e câmaras especializadas sobre o assunto, tal como já vem ocorrendo na justiça de alguns Estadosmembros: Tribunal de Justiça do Piauí e o Tribunal de Justiça do Rio de Janeiro. 
Dessa maneira, além do aprofundamento na área, as câmaras especializadas teriam outra função: planejar e fomentar a utilização de métodos alternativos de solução de conflitos, como a conciliação e a mediação. Trata-se de uma medida eficaz que desafoga a justiça e direciona os julgadores para examinar questões, exclusivamente, sobre saúde. Mas, de toda forma, é importante que a primeira e a segunda instância desenvolvam as suas funções jurisdicionais de forma compatível com a jurisprudência das cortes superiores, que possuem amplo e sedimentado entendimento sobre a matéria.

\section{REFERÊNCIAS}

Agência Nacional de Saúde Suplementar (ANS). Relatório Anual de Gestão: exercício 2020. Rio de Janeiro: ANS,2021. Disponível em: https://www.gov.br/ans/ptbr/arquivos/acesso-a-informacao/transparencia-institucional/prestacao-decontas/relatorios-de-gestao/relatorio-gestao-2020.pdf. Acesso em: 10 jul. 2021.

ASSESSORIA DE IMPRENSA DO TJRJ (Rio de Janeiro). Tribunal de Justiça do Rio de Janeiro (ed.). TJRJ regulamenta funcionamento das câmaras especializadas em Direito do Consumidor. 2013. Disponível em: http://www.tjrj.jus.br/noticias/noticia//visualizar-conteudo/5111210/5155709. Acesso em: 11 jul. 2021.

ASSIS, Araken de; ALVIM NETO, José Manoel de Arruda; ALVIM, Eduardo Arruda. Comentários ao Código de Processo Civil. Rio de Janeiro: Editora GZ, 2012.

BRAGA NETTO, Felipe Peixoto. Manual de Direito do Consumidor: à luz da jurisprudência do STJ. 15 ed. Salvador: Editora JusPodivm, 2020.

BRASIL. Lei $\mathrm{n}^{\circ}$ 9.656, de 3 de junho de 1998. Dispõe sobre os planos e seguros privados de assistência à saúde. DOU. Brasília/DF, 04 jun. 1998. Disponível em: http://www.planalto.gov.br/ccivil_03/leis/19656compilado.htm. Acesso em: 10 jul. 2021.

Decreto-Lei no 4.657, de 4 de setembro de 1942. Lei de Introdução às normas do Direito Brasileiro. DOU. Brasília/DF, 09 set. 1942. Disponível em: http://www.planalto.gov.br/ccivil_03/decreto-lei/del4657compilado.htm. Acesso em: 10 jul. 2021.

Lei $\mathrm{n}^{\circ}$ 12.376, de 30 de dezembro de 2010. Altera a ementa do Decreto-Lei no 4.657, de 4 de setembro de 1942. DOU. Brasília/DF, 31 dez. 2010. Disponível em: http://www.planalto.gov.br/ccivil_03/_Ato2007-2010/2010/Lei/L12376.htm\#art2. Acesso em: 10 jul. 2021. 
Resolução de Diretoria Colegiada (RDC) no 11, de 26 de janeiro de 2006. Dispõe sobre o Regulamento Técnico de Funcionamento de Serviços que prestam Atenção Domiciliar. DOU. Brasília/DF, 30 jan. 2006. n. 21, Seção 1. Disponível em: http://antigo.anvisa.gov.br/documents/10181/2718376/RDC_11_2006_COMP.pdf/6b69 c9b9-1edb-4424-b0cf-ec9f85f6f54c. Acesso em: 10 jul. 2021.

Superior Tribunal de Justiça. Agravo Interno no Agravo em Recurso Especial $n^{\circ}$ 1759394/SP. Agravante Amil Assistência Médica Internacional S.A. Relator: Ministro Moura Ribeiro. Brasília/DF, 22 de junho de 2021. DOU. Brasília, 25 jun. 2021. Disponível em: https://scon.stj.jus.br/SCON/GetInteiroTeorDoAcordao?num_registro=202002385715\& dt_publicacao=25/06/2021. Acesso em: 10 jul. 2021.

Superior Tribunal de Justiça. Agravo Interno no Agravo em Recurso Especial $\mathrm{n}^{\circ}$ 1119470/PE. Agravante GEAP Auto Gestão em Saúde. Relator: Ministro Marco Aurélio Belizze. Brasília/DF, 24 de outubro de 2017. DOU. Brasília, 6 nov. 2017. Disponível em:

https://scon.stj.jus.br/SCON/GetInteiroTeorDoAcordao?num_registro=201701400203\& dt_publicacao=06/11/2017. Acesso em: 10 jul. 2021.

Lei 9.961, de 28 de janeiro de 2000. Cria a Agência Nacional de Saúde Suplementar (ANS) e dá outras providências. DOU. Brasília/DF, 29 jan. 2000. Disponível em: http://antigo.anvisa.gov.br/documents/10181/2718376/RDC_11_2006_COMP.pdf/6b69 c9b9-1edb-4424-b0cf-ec9f85f6f54c. Acesso em: 10 jul. 2021.

Superior Tribunal de Justiça. Agravo Interno no Agravo em Recurso Especial

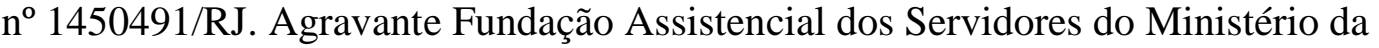
Fazenda. Relator: Ministro Paulo de Tarso Sanseverino. Brasília/DF, 8 de junho de 2020. DOU. Brasília, 12 jun. 2020. Disponível em: https://scon.stj.jus.br/SCON/GetInteiroTeorDoAcordao?num_registro=201900539143\& dt_publicacao=12/06/2020. Acesso em: 10 jul. 2021.

Superior Tribunal de Justiça. Agravo Interno no Agravo em Recurso Especial $\mathrm{n}^{\text {o }}$ 1586923/RJ. Agravante Fundação Assistencial dos Servidores do Ministério da Fazenda. Relator: Ministro Paulo de Tarso Sanseverino. Brasília/DF, 7 de maio de 2021. DOU. Brasília, 20 mai. 2021. Disponível em:

https://scon.stj.jus.br/SCON/GetInteiroTeorDoAcordao?num_registro=201902830959\& dt_publicacao=20/05/2021. Acesso em: 10 jul. 2021.

Supremo Tribunal Federal (STF). A Constituição e o Supremo. Supremo Tribunal Federal. 6 ed. atual. Até a EC 99/2017. Brasília: STF, Secretaria de Documentação, 2018.

Superior Tribunal de Justiça. Recurso Especial no 1.662.103/SP. Recorrente Unimed De Araraquara Cooperativa De Trabalho Médico. Relator: Ministra Nancy 
Andrighi. Brasília/DF, 11 de dezembro de 2018. DOU. Brasília, 13 dez. 2018.

Disponível em:

https://processo.stj.jus.br/processo/revista/documento/mediado/?componente=ATC\&seq uencial $=90450865 \&$ num_registro $=201700554365 \&$ data $=20181213 \&$ tipo $=91 \&$ formato $=$ PDF. Acesso em: 11 jul. 2021.

Superior Tribunal de Justiça. Agravo Interno no Agravo em Recurso Especial no 835.892/MA. Agravante GEAP Autogestão em Saúde. Relator: Ministro Antônio Carlos Ferreira. Brasília/DF, 27 de agosto de 2019. DOU. Brasília, 30 ago. 2019. Disponível em: https://processo.stj.jus.br/processo/revista/documento/mediado/?componente=ATC\&seq uencial $=99362969 \&$ num_registro $=201503241629 \&$ data $=20190830 \&$ tipo $=91 \&$ formato $=$ PDF. Acesso em: 11 jul. 2021.

Superior Tribunal de Justiça. Recurso Especial no 181.6768/PR. Recorrente: Unimed Do Estado Do Paraná - Federação Estadual Das Cooperativas Médicas. Relator: Ministro Paulo de Tarso Sanseverino. Brasília/DF, 15 de dezembro de 2020. DOU. Brasília, 18 dez. 2020. Disponível em:

https://scon.stj.jus.br/SCON/GetInteiroTeorDoAcordao?num_registro=201801520662\& dt_publicacao=18/12/2020. Acesso em: 11 jul. 2021.

Lei $n^{\circ} 8.078$, de 111990 . Dispõe sobre a proteção do consumidor e dá outras providências. DOU. Brasília/DF, 12 set. 1990. Disponível em: http://www.planalto.gov.br/ccivil_03/leis/18078compilado.htm. Acesso em: 11 jul. 2021.

Superior Tribunal de Justiça. Recurso Especial nº 1726563/SP. Recorrente: Amil Assistência Médica Internacional S.A. Relator: Ministro Moura Ribeiro. Brasília/DF, 8 de novembro de 2018. DOU. Brasília, 26 nov. 2018. Disponível em: https://processo.stj.jus.br/processo/pesquisa/?tipoPesquisa=tipoPesquisaNumeroRegistr o\&termo=201701201853. Acesso em: 11 jul. 2021.

Superior Tribunal de Justiça. Recurso Especial no 1712163/SP. Recorrente: Amil Assistência Médica Internacional S.A. Relator: Ministro Moura Ribeiro. Brasília/DF, 13 de março de 2018. DOU. Brasília, 19 mar. 2018. Disponível em: https://processo.stj.jus.br/SCON/GetInteiroTeorDoAcordao?num_registro=2017012018 53\&dt_publicacao=19/03/2018. Acesso em: 11 jul. 2021.

Superior Tribunal de Justiça. Recurso Especial n ${ }^{\circ}$ 1.692.938/SP. Recorrente: Omint Serviços de Saúde LTDA. Relator: Ministro Ricardo Villas Bôas Cueva. Brasília/DF, 15 de dezembro de 2020. DOU. Brasília, 18 dez. 2020. Disponível em: https://processo.stj.jus.br/processo/revista/documento/mediado/?componente=ATC\&seq uencial $=123753268 \&$ num_registro $=201702199675 \&$ data $=20210504 \&$ tipo $=91 \&$ format $\mathrm{o}=$ PDF. Acesso em: 11 jul. 2021. 
Resolução Normativa $n^{\circ} 310$, de 30 de outubro de 2012. Dispõe sobre os princípios para a oferta de contrato acessório de medicação de uso domiciliar pelas operadoras de planos de assistência à saúde. DOU. Brasília/DF, 31 out. 2012.

Disponível em:

https://bvsms.saude.gov.br/bvs/saudelegis/ans/2012/res0310_30_10_2012.html. Acesso em: 11 jul. 2021.

. Superior Tribunal de Justiça. Agravo Interno no Agravo em Recurso Especial 1450651/SP. Recorrente: Amil Assistência Médica Internacional S.A. Relator: Ricardo Villas Bôas Cueva. Brasília/DF, 16 de setembro de 2019. DOU. Brasília, 18 set. 2019. Disponível em:

https://scon.stj.jus.br/SCON/GetInteiroTeorDoAcordao?num_registro=201900558681\& dt_publicacao=18/09/2019. Acesso em: 11 jul. 2021.

Lei $\mathrm{n}^{\circ}$ 10.406, de 10 de janeiro de 2002. Institui o Código Civil. DOU. Brasília/DF, 11 jan. 2002. Disponível em: http://www.planalto.gov.br/ccivil_03/leis/2002/110406compilada.htm. Acesso em: 11 jul. 2021.

Código de processo civil e normas correlatas. 9. ed. Brasília: Senado Federal, Coordenação de Edições Técnicas, 2016.

Conselho Nacional de Justiça (CNJ). Poder Judiciário. Judicialização da

Saúde no Brasil: perfil das demandas, causas e propostas de solução. Brasília:

INSPER, 2019, p. 13. Disponível em: https://www.cnj.jus.br/wp-

content/uploads/2019/03/66361404dd5ceaf8c5f7049223bdc709.pdf. Acesso em: 11 jul. 2021.

CEARÁ, Tribunal de Justiça do (org.). Núcleo que auxilia juízes em demandas de Saúde será ampliado para região Sul do Estado. 2020. Elaborado pela Imprensa do TJCE. Disponível em: https://www.tjce.jus.br/noticias/nucleo-que-auxilia-juizes-emdemandas-de-saude-sera-ampliado-para-regiao-sul-do-estado/. Acesso em: 11 jul. 2021.

DWORKIN, Ronald. M. Levando os direitos a sério. Trad. Nelson Boeira. São Paulo: Martins Fontes, 2002.

HÄRBELE, Peter. El Estado Constitucional. Tradução de Héctor Fix-Fierro. México: Universidad Nacional Autónoma de México, 2003.

LEITE, Miguel Torres. Saúde suplementar no Brasil: cenário atual pede atenção. 2021. Elaborado pela Medicina S/A. Disponível em: https://medicinasa.com.br/saudesuplementar-no-brasil/. Acesso em: 11 jul. 2021.

SILVA, Daniel. $4^{\text {a }}$ Câmara de Direito Pública terá competência específica para julgar demandas da saúde pública. 2018. Elaborado por Ascom TJ-PI. Disponível 
em: http://www.tjpi.jus.br/portaltjpi/tjpi/noticias-tjpi/4a-camara-de-direito-publica-teracompetencia-especifica-para-julgar-demandas-da-saude-publica/. Acesso em: 11 jul.

2021.

TUCCI, José Rogério Cruz e. Precedente Judicial como Fonte do Direito. São Paulo: Revista dos Tribunais, 2004.

Recebido em: 20/10/2021

Aprovado em: 20/11/2021

Publicado em: 25/11/2021 